\title{
Dynamics of Exploding Plasma within a Magnetized Plasma
}

G. Dimonte, G. DiPeso, D. Hewett

February 1, 2002 


\section{DISCLAIMER}

This document was prepared as an account of work sponsored by an agency of the United States Government. Neither the United States Government nor the University of California nor any of their employees, makes any warranty, express or implied, or assumes any legal liability or responsibility for the accuracy, completeness, or usefulness of any information, apparatus, product, or process disclosed, or represents that its use would not infringe privately owned rights. Reference herein to any specific commercial product, process, or service by trade name, trademark, manufacturer, or otherwise, does not necessarily constitute or imply its endorsement, recommendation, or favoring by the United States Government or the University of California. The views and opinions of authors expressed herein do not necessarily state or reflect those of the United States Government or the University of California, and shall not be used for advertising or product endorsement purposes.

This work was performed under the auspices of the U.S. Department of Energy by the University of California, Lawrence Livermore National Laboratory under Contract No. W-7405-Eng-48.

This report has been reproduced directly from the best available copy.

Available electronically at http://www.doe.gov/bridge

Available for a processing fee to U.S. Department of Energy

and its contractors in paper from

U.S. Department of Energy

Office of Scientific and Technical Information

P.O. Box 62

Oak Ridge, TN 37831-0062

Telephone: (865) 576-8401

Facsimile: (865) 576-5728

E-mail: reports@adonis.osti.gov

Available for the sale to the public from

U.S. Department of Commerce

National Technical Information Service

5285 Port Royal Road

Springfield, VA 22161

Telephone: (800) 553-6847

Facsimile: (703) 605-6900

E-mail: orders@ntis.fedworld.gov

Online ordering: http://www.ntis.gov/ordering.htm

OR

Lawrence Livermore National Laboratory

Technical Information Department's Digital Library

http://www.llnl.gov/tid/Library.html 


\title{
Dynamics of exploding plasma within a magnetized plasma
}

\author{
Guy Dimonte, Greg DiPeso, Dennis Hewett, LLNL
}

Feb 1, 2002

This memo describes several possible laboratory experiments on the dynamics of an exploding plasma in a background magnetized plasma. These are interesting scientifically and the results are applicable to energetic explosions in the earth's ionosphere (DOE Campaign 7 at LLNL). These proposed experiments are difficult and can only be performed in the new LAPD device at UCLA. The purpose of these experiments would be to test numerical simulations, theory and reduced models for systems performance codes. The experiments are designed to investigate the affect of the backgorund plasma on

(1) the maximum diamagnetic bubble radius given by Eq. 9 below

(2) the Alfven wave radiation efficiency produced by the induced current $\mathrm{J}_{\mathrm{A}}$ (Eqs. 10-12)

These experiments involve measuring the bubble radius using a fast gated optical imager as in Ref [1] and the Alfven wave profile and intensity as in Ref [2] for different values of the exploding plasma energy, background plasma density and temperature, and background magnetic field. These experiments extend the previously successful experiments [2] on Alfven wave coupling. We anticipate that the proposed experiments would require 1-2 weeks of time on the LAPD. We would perform PIC simulations in support of these experiments in order to validate the codes. Once validated, the PIC simulations would then be able to be extended to realistic ionospheric conditions with various size explosions and altitudes. In addition to the Alfven wave coupling, we are interested in the magnetic containment and transport of the exploding "debris" plasma to see if the shorting of the radial electric field in the magnetic bubble would allow the ions to propagate further. This has important implications in an ionospheric explosion because it defines the satellite damage region. In these experiments, we would field fast gated optical cameras to obtain images of the plasma expansion, which could then be correlated with magnetic probe measurements. In this regard, it would be most helpful to have a more powerful laser more than 10J in order to increase the extent of the magnetic bubble.

\section{Background}

Consider an exploding plasma with total energy $E_{d}$ and total number of ions $N_{d}$ expanding into a vacuum magnetic field $B$. If the ions are unmagnetized, they are stopped a radius $R_{b o}$ given by

$$
\text { e } E R_{b o} \sim E_{d} / N_{d}
$$

where $\mathrm{E}$ is an electric field that develops between the ions and magnetized electrons. This field produces an electron drift current

$$
\mathrm{J}_{\theta} \sim\left(\mathrm{N}_{\mathrm{d}} / 4 \pi \mathrm{R}_{\mathrm{bo}}{ }^{2} \mathrm{~d}\right) \mathrm{ecE} / \mathrm{B}
$$

Where $d$ is the radial thickness of the exploding plasma. This current produces a diamagnetic field perturbation

$$
\delta \mathrm{B} \sim 4 \pi \mathrm{J}_{\theta} \mathrm{d} / \mathrm{c} \sim / \mathrm{R}_{\mathrm{bo}}{ }^{3} \mathrm{~B}
$$


Equations 1-3 can then be rewritten as

$$
E_{d}=\frac{B^{2}}{8 \pi} \frac{4 \pi R_{b o}^{3}}{3}
$$

which is interpreted as energy balance, namely, that the final radius of the diamagnetic cavity produced the exploding plasma is obtained when its total kinetic energy equals the total displaced magnetic energy. This has been checked [1] for a plasma exploding into a vaccum.

However, there are two complications when there is a magnetized background plasma of number density $n_{0}$. First, the background plasma is swept up by the exploding plasma and must be energized by it such that energy balance is modified to

$$
E_{d}=\frac{B^{2}}{8 \pi} \frac{4 \pi R_{b}^{3}}{3}+\frac{\rho_{o} V_{d}^{2}}{2} \frac{4 \pi R_{b}^{3}}{3}
$$

where $\rho_{0}$ is the mass density of the background plasma and $V_{d}$ is the expansion velocity of the exploding plasma. This effectively reduces the maximum radius of the diamagnetic cavity to

$$
\frac{R_{b}}{R_{b o}} \sim\left[1+\left(\frac{V_{v}}{V_{A}}\right)^{2}\right]^{-1 / 3}
$$

The second effect has both local and global implications in that the electric field in Eq. 1 can be shorted out by electron currents in the background plasma. This will reduce the depth of the diamagnetic cavity $\delta \mathrm{B}$ and also the retarding force on the expanding ions so that they will be transported to larger radius. In addition, the induced current $\mathrm{J}_{\mathrm{A}}$ in the background plasma will generate Alfven waves. Using Ampere's lae, the Alfven wave magnetic field is

$$
\mathrm{B}_{\mathrm{A}} \sim \mathrm{J}_{\mathrm{A}} \mathrm{R}_{\mathrm{b}} 2 \pi / \mathrm{c}
$$

with a period of $3 R_{b} / V_{d}$. Then, the energy radiated into Alfven waves can be estimated as

$$
E_{A}=\frac{B_{A}^{2}}{8 \pi} 2 \pi R_{b}^{2} V_{A} \frac{3 R_{b}}{V_{d}} \sim \frac{3 \pi^{2}}{c^{2}} J_{A}^{2} \frac{V_{A}}{V_{d}} R_{b}^{5}
$$

The should be included in energy balance

$$
E_{d}=\frac{B^{2}}{8 \pi} \frac{4 \pi R_{b}^{3}}{3}+\frac{\rho_{0} V_{d}^{2}}{2} \frac{4 \pi R_{b}^{3}}{3}+E_{A}
$$

These affects are important for modelling an energetic explosion in the ionosphere because the energetic plasma can destroy satelites and the Alfven waves can propogate over the entir earth and induce power disruption. Such effects are difficult to calculate and must be checked with experiments, such as those proposed here.

\section{Proposed study}

They key uncertainty in this model is the magnitude and distribution of the Alfven wave current induced in the background plasma. Initial experiments [2] performed to measure this current in the LAPD obtained very interesting results. PIC simulations of these experiments obtain $\mathrm{J}_{\mathrm{A}} \sim 10^{10}$ statamps $/ \mathrm{cm}^{2}$ for LAPD conditions, $\mathrm{n}_{\mathrm{o}} \sim 210^{12} \mathrm{~cm}^{-3}$ and $\mathrm{V}_{\mathrm{d}} \sim 10^{7} \mathrm{~cm} / \mathrm{s}$. Such a value can be obtained by using the plasma expansion speed 


$$
\mathrm{J}_{\mathrm{A}} \sim \mathrm{n}_{\mathrm{o}} \mathrm{e}_{\mathrm{d}} \sim 10^{10} \text { statamp } / \mathrm{cm}^{2}
$$

or the Alfven speed

$$
\mathrm{J}_{\mathrm{A}} \sim 0.1 \mathrm{n}_{\mathrm{o}} \mathrm{eV}_{\mathrm{A}} \sim 10^{10} \text { statamp } / \mathrm{cm}^{2}
$$

or the electron thermal speed at $\mathrm{T}_{\mathrm{e}} \sim 2 \mathrm{eV}$

$$
\mathrm{J}_{\mathrm{A}} \sim 0.1 \mathrm{n}_{\mathrm{o}} \text { e } \mathrm{V}_{\mathrm{e}} \sim 10^{10} \mathrm{statamp} / \mathrm{cm}^{2}
$$

It is important to differentiate among these "explanation" because they will predict very different values for a hypothetical megaton explosion at $400 \mathrm{~km}$ height in the ionosphere [3, 4]. For these conditions, $\mathrm{n}_{\mathrm{o}} \sim 210^{5} \mathrm{~cm}^{-3}, \mathrm{~B} \sim 0.3 \mathrm{~g}, \mathrm{~T}_{\mathrm{e}}<0.1 \mathrm{eV}, \mathrm{V}_{\mathrm{d}} \sim 1.510^{8} \mathrm{~cm} / \mathrm{s}, \mathrm{E}_{\mathrm{d}} \sim 10^{22} \mathrm{ergs}$, we estimate very different values of

$$
\mathrm{J}_{\mathrm{A}} \sim \mathrm{n}_{\mathrm{o}} \text { e } \mathrm{V}_{\mathrm{d}} \sim 15,000 \text { statamp } / \mathrm{cm}^{2}
$$

or

$$
\mathrm{J}_{\mathrm{A}} \sim 0.1 \mathrm{n}_{\mathrm{o}} \mathrm{e} \mathrm{V}_{\mathrm{A}} \sim 500 \text { statamp } / \mathrm{cm}^{2}
$$

or

$$
\mathrm{J}_{\mathrm{A}} \sim 0.1 \mathrm{n}_{\mathrm{o}} \mathrm{eV}_{\mathrm{e}}<200 \text { statamp/cm } \mathrm{cm}^{2}
$$

These differences are very important since the Alfven wave radiation efficiency scales as $\mathrm{J}_{\mathrm{A}}{ }^{2}$.

In addition to measuring the wave coupling, it is important to obtain gated images of the exploding plasma in order to ascertain how far it is transported. This can be done with our Gated Optical Imager (GOI) and the associated CCD cameras. These images can then be compared to magnetic probe measurements in the local magnetic bubble. They can also be compared with images taken at LLNL in a vacuum magnetic field in which strong Rayleigh-Taylor type instabilities caused spikes of plasma to be transported well beyond the magnetic containment radius.

This work was performed under the auspices of the U.S. Department of Energy by the Lawrence Livermore National Laboratory under Contract No. W-7405-ENG-48.

\section{References}

[1] Guy Dimonte and Larry Wiley, Phys Rev Lett 67, 1755 (1991)

[2] M. VanZeeland, et al, Phys Rev Lett 87, (2001)

[3] J Zinn, "Motion of bomb debris following STARFISH test" in Radiation trapped in Earth's magnetic field, BM McCormac, ed, Gordon and Breach/Science Pub, NY 1966, p. 671

[4] Series of articles on STARFISH including wave generation in J. Geo. Res 68, pp. 605-745 (1963) 


\section{Disclaimer:}

This document was prepared as an account of work sponsored by an agency of the United States Government. Neither the United States Government nor the University of California nor any of their employees, makes any warranty, express or implied, or assumes any legal liability or responsibility for the accuracy, completeness, or usefulness of any information, apparatus, product, or process disclosed, or represents that its use would not infringe privately owned rights. References herein to any specific commercial products, process, or service by trade name, trademark, manufacturer, or otherwise, does not necessarily constitute or imply its endorsement, recommendation, or favoring by the United States Government. or the University of California. The views and opinions of authors expressed herein do not necessarily state or reflect those of the United States Government or the University of California, and shall not be used for advertising or product endorsement purposes. 